\title{
p53 Protein Accumulation and Presence of Visceral Metastasis Are Independent Prognostic Factors for Survival in Patients with Metastatic Inflammatory Breast Carcinoma
}

\author{
Canfeza Sezgin $^{\mathrm{a}} \quad$ Erhan Gokmen $^{\mathrm{a}}$ Murat Kapkac $^{\mathrm{b}}$ Osman Zekioglu ${ }^{\mathrm{c}}$ \\ Mustafa Esassolak ${ }^{d}$ Bulent Karabulut ${ }^{a}$ Ulus Ali Sanli ${ }^{a}$ Ruchan Uslu ${ }^{a}$ \\ Departments of ${ }^{\mathrm{a}}$ Internal Medicine (Division of Medical Oncology), ${ }^{\mathrm{b}}$ General Surgery, ${ }^{\mathrm{C}}$ Pathology and \\ ${ }^{\mathrm{d}}$ Radiation Oncology, Ege University Medical Faculty, Izmir, Turkey
}

\section{Key Words}

Breast carcinoma, inflammatory $\cdot$ Prognostic factors $\cdot$ p53 •

Survival, breast carcinoma

\begin{abstract}
Objective: The aim of this study was to determine the markers of prognosis in metastatic inflammatory breast cancer (IBC). Subjects and Methods: The prognostic value of patients' clinical characteristics and expression of c-erbB-2, p53, Ki-67, ER and PgR were assessed in the 45 patients with IBC who had developed distant metastasis. Immunohistochemical methods were used to detect the expression of c-erbB-2, p53, Ki-67, ER and PgR in surgical resection specimens of the patients' primary tumor. Results: The median overall survival (OS) measured from the diagnosis of metastatic disease was 23 months. In the univariate analysis, p53 protein accumulation and the presence of visceral metastasis were predictive of poor survival ( $p=0.01$ and 0.003 , respectively). In the multivariate analysis, accumulation of p53 protein and the presence of visceral metastasis correlated with OS ( $p=0.02$ and 0.008 , respectively). Conclusion: In metastatic IBC, accumulation of $\mathrm{p} 53$ protein and presence of visceral metastasis are independent prognostic factors for OS. Established prognostic factors in non-IBC patients such
\end{abstract}

as patient age, histologic grade, hormone receptor status and c-erbB-2 status did not have independent significance in IBC in this study.

Copyright $\odot 2011$ S. Karger AG, Basel

\section{Introduction}

Inflammatory breast cancer (IBC) is an aggressive form of the disease accounting for $1-5 \%$ of all breast cancers [1]. The clinical characteristics of IBC include skin erythema, edema, peau d'orange, tenderness, induration, warmth and enlargement of the breast, and nearly all patients have axillary lymph node involvement at the time of the diagnosis $[2,3]$. Pathologically, IBC presents with dermal lymphatic invasion [2]. The management of patients with locally advanced IBC requires a multimodality approach involving systemic chemotherapy, surgery and radiotherapy $[4,5]$.

With regards to the clinical course following primary therapy, locally advanced IBC is a heterogeneous disease. Although the prognosis of IBC is poorer when compared with noninflammatory locally advanced breast cancers, there is a minority of the patients who enjoy a longer disease-free survival [1]. Among the prognostic factors ana- 
lyzed in the few studies focusing on IBC, absence of p53 mutations appeared to predict longer disease-free and overall survival (OS) following primary therapy [6-8]. The clinical course of metastatic IBC, however, has not been thoroughly investigated. It is unknown whether the established prognostic markers in metastatic non-IBC have significance in IBC as well. Because IBC is a relatively rare disease, the majority of the available data are derived from small single-arm clinical trials and retrospective reviews and relate to nonmetastatic IBC $[5,6,8$, 9]. The aim of this study was to determine the prognostic markers in metastatic IBC.

\section{Subjects and Methods}

A total of 68 consecutive patients with IBC were treated with a curative intent at the Division of Medical Oncology, Ege University School of Medicine, between 1993 and 2002. In all the patients, upfront management consisted of surgery, adjuvant radiotherapy and systemic chemotherapy in a neoadjuvant and/or adjuvant setting and adjuvant hormonal therapy in hormonereceptor-positive patients. The diagnosis of IBC required the presence of erythema, warmth, ridging and peau d'orange appearance of the breast with evidence of dermal lymphatic invasion on pathological evaluation. All patients had baseline assessments of complete blood count, as well as renal and hepatic function tests. Imaging studies before treatment included chest X-ray, abdominal ultrasound and radionuclide bone scan. Computed tomography (CT) scans of the chest, abdomen and pelvis were done when deemed necessary by the treating physician. Chest X-ray, abdominal ultrasound and laboratory studies were repeated every 3 months.

All patients underwent total mastectomy. Except for 1 patient with cardiomyopathy, all patients received an anthracycline-containing regimen either in the neoadjuvant or adjuvant setting. Sixteen patients received neoadjuvant and 44 patients received adjuvant chemotherapy. In the 25 patients, the adjuvant chemotherapy included a taxane. All patients were given adjuvant radiotherapy. Antiestrogen therapy was given to the 21 hormone-receptor-positive patients. A median of 3 chemotherapy regimens (range $=0-7$ ) were administered for metastatic IBC. Chemotherapies in the metastatic setting included docetaxel, paclitaxel, gemcitabine and vinorelbine. In 10 patients, the treatment also included trastuzumab. In 29 patients, first-line chemotherapy included a taxane, while 10 patients had vinorelbine alone or in combination with gemcitabine.

Fifty-seven patients developed metastasis during follow-up. Twelve patients lost to follow-up were excluded. The remaining 45 patients with metastatic IBC were included in this study. Before the initiation of treatment for metastatic IBC, each patient had an ECG, chest X-ray, abdominal ultrasound, and CT scans of the chest and abdomen. Histologic proof of IBC and radiographic evidence of metastatic disease with at least 1 measurable or assessable lesion were required. Medical history, physical examination, Eastern Cooperative Oncology Group performance status and laboratory tests (hematology, blood chemistry) were also ob-
Table 1. Patients and tumor characteristics

\begin{tabular}{|c|c|c|}
\hline Variable & $\mathrm{n}$ & $\%$ \\
\hline All patients & 45 & 100 \\
\hline Median age, years & 43 & - \\
\hline \multicolumn{3}{|l|}{ Histology } \\
\hline IDC & 39 & 87 \\
\hline IDC/ILC & 5 & 11 \\
\hline ILC & 1 & 2 \\
\hline \multicolumn{3}{|l|}{ Histologic grade } \\
\hline II & 13 & 29 \\
\hline III & 30 & 67 \\
\hline Unknown & 2 & 4 \\
\hline \multicolumn{3}{|l|}{ Number of lymph node metastases } \\
\hline$<4$ & 5 & 11 \\
\hline $4-9$ & 18 & 40 \\
\hline$\geq 10$ & 21 & 47 \\
\hline Unknown & 1 & 2 \\
\hline \multicolumn{3}{|l|}{ Hormone receptor status } \\
\hline Positive & 21 & 47 \\
\hline Negative & 24 & 53 \\
\hline \multicolumn{3}{|l|}{ c-erbB-2 } \\
\hline Overexpressed & 24 & 53 \\
\hline Not overexpressed & 21 & 47 \\
\hline \multicolumn{3}{|l|}{ p53 } \\
\hline Positive & 23 & 51 \\
\hline Negative & 22 & 49 \\
\hline \multicolumn{3}{|l|}{$\mathrm{Ki}-67^{\circ}$} \\
\hline Positive & 23 & 51 \\
\hline Negative & 22 & 49 \\
\hline \multicolumn{3}{|l|}{ Site of first recurrence } \\
\hline Visceral & 30 & 67 \\
\hline Nonvisceral & 15 & 33 \\
\hline Prior neoadjuvant chemotherapy & 16 & 36 \\
\hline Prior adjuvant chemotherapy & 44 & 98 \\
\hline Prior adjuvant antiestrogen therapy & 19 & 42 \\
\hline Prior adjuvant radiotherapy & 45 & 100 \\
\hline \multicolumn{3}{|l|}{ Anthracycline-based chemotherapy } \\
\hline (neoadjuvant and/or adjuvant setting) & 44 & 98 \\
\hline \multicolumn{3}{|l|}{ Taxane-based chemotherapy } \\
\hline (neoadjuvant and/or adjuvant setting) & 25 & 56 \\
\hline
\end{tabular}

IDC = Invasive ductal carcinoma; ILC = invasive lobular carcinoma.

tained. Complete blood counts and serum biochemistry were performed at the beginning of each chemotherapy cycle. Radiological assessments were repeated at 8- to 9-week intervals. Response to treatment was assessed using WHO criteria [10]. Recurrences or metastases were classified as either visceral (lung, liver and other organs) or nonvisceral (lymph node, bone and skin involvement).

Expression of c-erbB-2, p53, Ki-67, ER and PgR was examined by immunohistochemistry. Immunohistochemical studies were performed on histological sections prepared from the biopsy sample taken before treatment. All tissues had been fixed in $4 \%$ buff- 

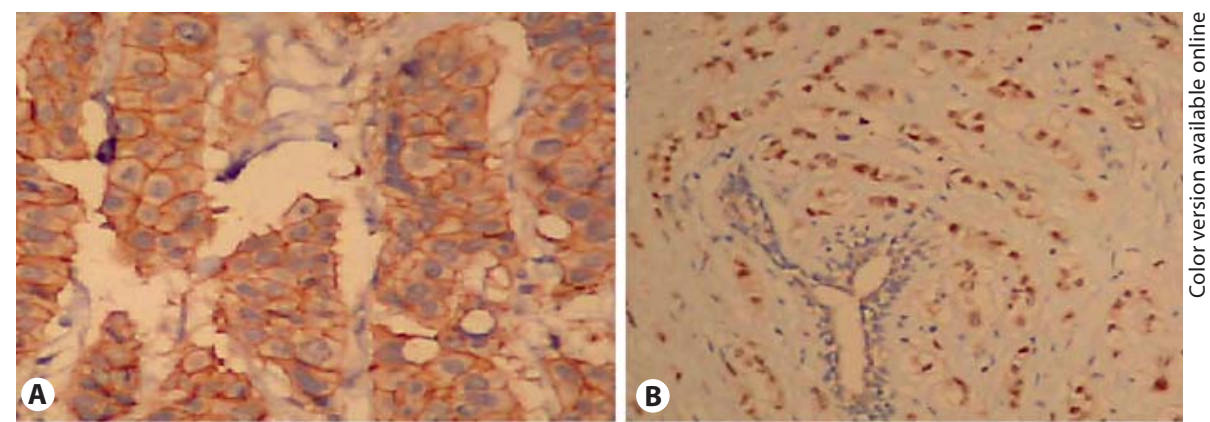

Fig. 1. Tissue section immunostained for c-erbB-2 overexpression (A), ER expression (B), high Ki-67 expression (C), and high p53 expression (D). $\times 200$.
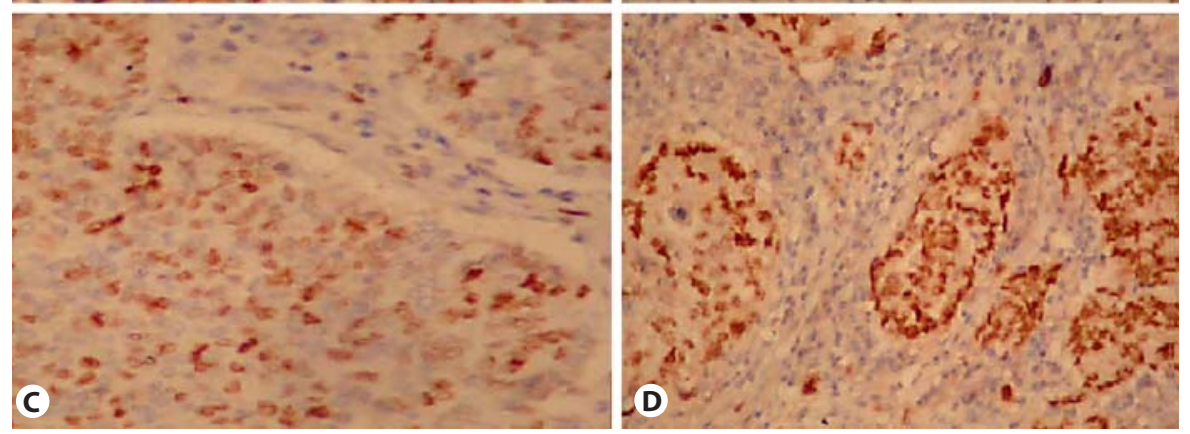

ered formalin, processed and embedded in paraffin according to the standard schedule used in the laboratory. From each block, 5 - $\mu \mathrm{m}$-thick sections were cut on coated slides and dried overnight at $37^{\circ} \mathrm{C}$. The sections were deparaffinized in xylene, rehydrated through graded concentrations of ethanol and distilled water and boiled in citrate buffer $(\mathrm{pH}=6.0)$ in a microwave oven for $20 \mathrm{~min}$. Immunohistochemical staining was performed by using a commercial ABC Kit (Lab Vision; Ultravision Large Volume Detection System Anti-Mouse, HRP, Calif., USA) directed against mouse IgG. Blocking serum was applied for $15 \mathrm{~min}$ followed by overnight incubation with the diluted monoclonal antibodies against c-erbB-2 (Dako, code No.: A0485, Denmark), ER (Dako, IDS code No.: M:7047, Denmark), PgR (Dako, PgR 636 code No.: M3569, Calif., USA), Ki-67 (Dako, code No.: A0047, Denmark) and p53 (Dako, clone D0-7, code No.: M7001, Denmark).

Cells were considered positive for ER, PgR, p53 and Ki-67 when distinct nuclear staining was identified. A $10 \%$ cutoff point was chosen to designate tumor cells as having negative or positive p53 and Ki-67 expressions. Tumor specimens were considered positive for ER/PgR when $\geq 1 \%$ of the cells showed nuclear staining. c-erbB-2 expression was graded as $1+, 2+$ or $3+$ based on the intensity of staining in $>10 \%$ of the tumor cells. A score of $3+$ was used as the cutoff point for overexpression.

OS was defined as the time from the detection of the first metastasis to death. Kaplan Meier and log rank tests were used for the analysis of OS. Multivariate analysis was evaluated by stepwise forward Cox regression analysis. The Fisher exact test was used to assess the significance of association of p53 distribution in patients with visceral or nonvisceral metastasis. SPSS (SPSS Inc., Chicago, Ill., USA) v.11.5 was used for the statistical analysis. Differences in statistical tests were considered as significant when $\mathrm{p} \leq 0.05$.

Prognostic Factors in Inflammatory

Breast Carcinoma

\section{Results}

The patient characteristics are summarized in table 1. The median age was 43 years (range $=24-82$ ). Twenty-one patients $(47 \%)$ had c-erbB-2-negative or normal breast cancer, while c-erbB-2 was $3+$ in 24 patients (53\%) (fig. 1A). ER and/or PR were positive in 21 (47\%) and both receptors were negative in 24 patients (53\%) (fig. 1B). Twenty-two patients (49\%) had Ki-67-negative and 23 (51\%) had Ki-67positive tumors (fig. 1C). p53 expression was positive in 23 patients (51\%) and negative in 22 (49\%) (fig. 1D).

The objective response rate defined as the sum of complete and partial responses was 33\% for first-line chemotherapy. The median progression-free survival following first-line chemotherapy was 8.6 months (range $=1-37$ ).

At a median follow-up of 20 months from the detection of metastatic disease $[95 \%$ confidence interval $(\mathrm{CI})=$ 16.1-23.9), 13 patients (29\%) were alive. The median OS was 23 months $(95 \% \mathrm{CI}=18-28)$. In the univariate analysis, p53 accumulation and the presence of visceral metastasis were predictive of poor survival $(\mathrm{p}=0.01$ and 0.003 , respectively; table 2 ). In the multivariate analysis, accumulation of $\mathrm{p} 53$ protein and the presence of visceral metastasis remained to be the 2 significant predictors of poor OS ( $\mathrm{p}=0.02, \mathrm{HR}=2.49,95 \% \mathrm{CI}=1.13-5.44$ and $\mathrm{p}=0.008, \mathrm{HR}=3.46,95 \% \mathrm{CI}=1.39-8.60$, respectively). The median OS for the 22 patients with p53-negativetumors was 43 months. In contrast, the OS for the 23 pa- 


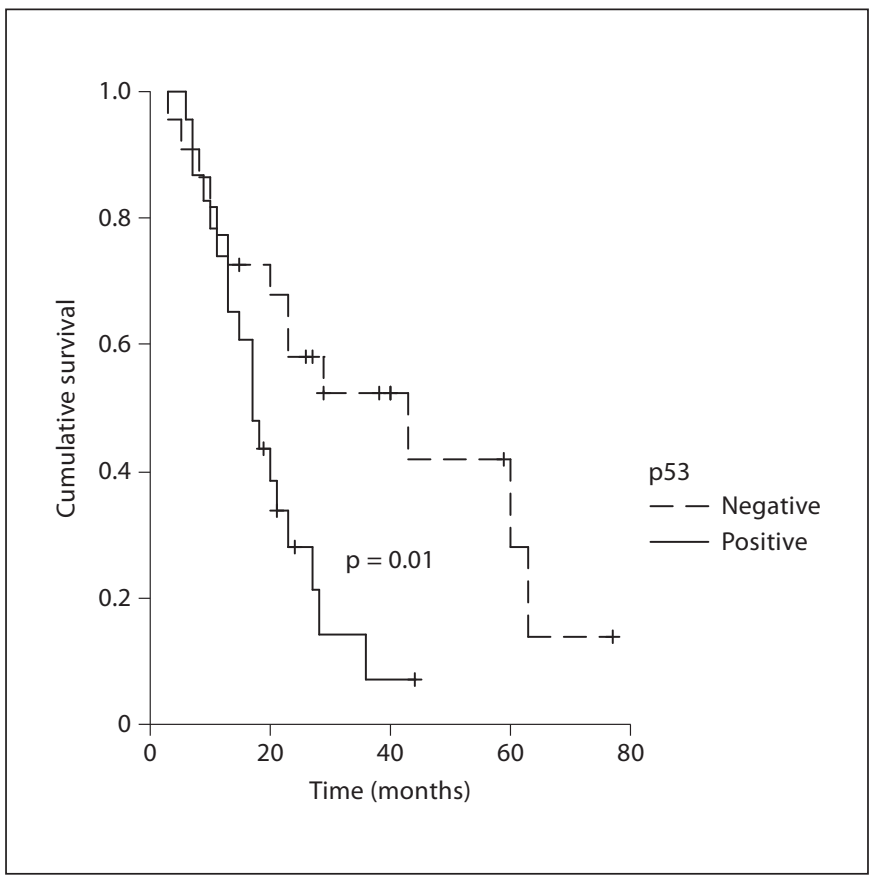

Fig. 2. Comparison of the p53 status with respect to OS: p53negative (upper curve, $\mathrm{n}=22$ ) versus $\mathrm{p} 53$-positive (lower curve, $\mathrm{n}=23)$.

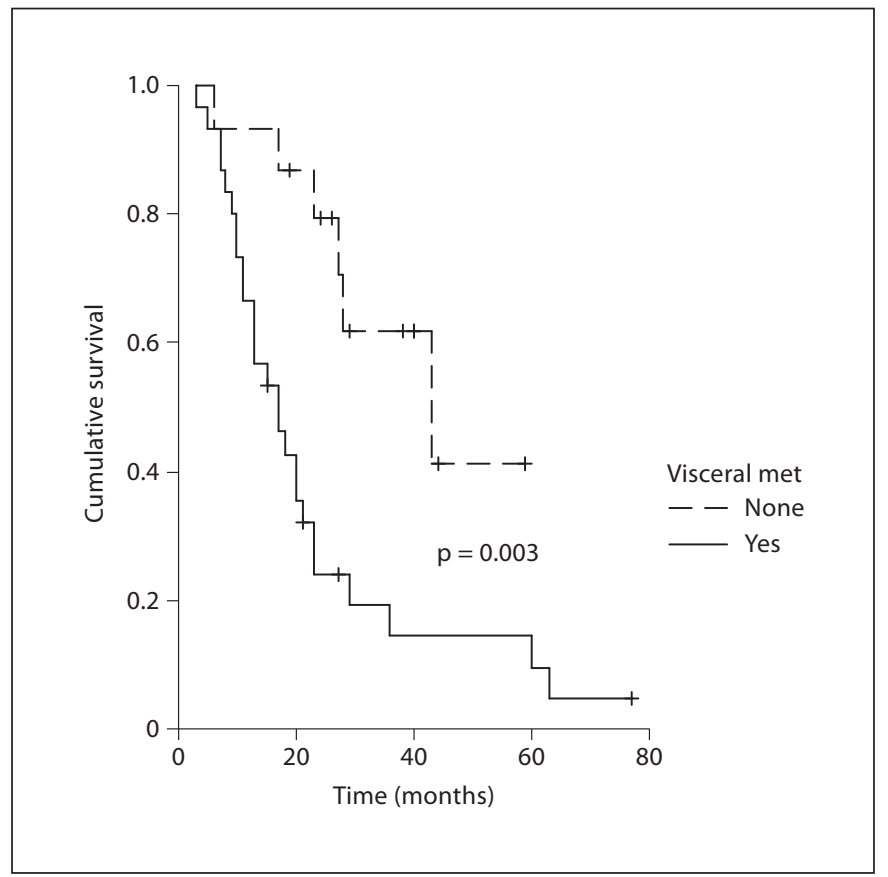

Fig. 3. Comparison of the nonvisceral metastasis and visceral metastasis patient groups with respect to OS: nonvisceral metastasis (upper curve, $\mathrm{n}=15$ ) versus visceral metastasis (lower curve, $\mathrm{n}=30)$.
Table 2. Univariate analysis of clinical and molecular markers predicting for overall survival

\begin{tabular}{|c|c|c|c|}
\hline Variable & $\begin{array}{l}\text { Median } \\
\text { survival } \\
\text { months }\end{array}$ & $\begin{array}{l}95 \% \text { CI } \\
\text { months }\end{array}$ & $\begin{array}{l}\text { p value } \\
\text { (log-rank } \\
\text { test) }\end{array}$ \\
\hline \multicolumn{4}{|l|}{ Patient age } \\
\hline$<50$ years & 23 & $17.9-28.1$ & \multirow[t]{2}{*}{0.41} \\
\hline$\geq 50$ years & 18 & $0.0-54.5$ & \\
\hline \multicolumn{4}{|l|}{ Histologic grade } \\
\hline II & 20 & $11.7-28.3$ & \multirow[t]{2}{*}{0.56} \\
\hline III & 23 & $11.5-34.5$ & \\
\hline \multicolumn{4}{|l|}{ Lymph node metastases } \\
\hline$<4$ & 18 & $15.9-20.1$ & \multirow[t]{3}{*}{0.71} \\
\hline $4-9$ & 21 & $10.2-31.8$ & \\
\hline$\geq 10$ & 27 & $16.4-37.6$ & \\
\hline \multicolumn{4}{|c|}{ Hormone receptor status } \\
\hline Positive & 21 & $17.0-25.0$ & \multirow[t]{2}{*}{0.74} \\
\hline Negative & 23 & $7.5-38.5$ & \\
\hline \multicolumn{4}{|l|}{ c-erbB-2 } \\
\hline Overexpressed & 23 & $19.6-26.4$ & \multirow[t]{2}{*}{0.98} \\
\hline Not overexpressed & 20 & $4.8-35.2$ & \\
\hline \multicolumn{4}{|l|}{ p53 } \\
\hline Positive & 17 & $13.5-20.5$ & \multirow[t]{2}{*}{0.01} \\
\hline Negative & 43 & $12.0-74.0$ & \\
\hline \multicolumn{4}{|l|}{$\mathrm{Ki}-67$} \\
\hline Positive & 21 & $16.1-25.9$ & \multirow[t]{2}{*}{0.37} \\
\hline Negative & 27 & $11.5-42.5$ & \\
\hline \multicolumn{4}{|l|}{ Site of first recurrence } \\
\hline Visceral & 17 & $10.6-23.4$ & \multirow[t]{2}{*}{0.003} \\
\hline Nonvisceral & 43 & $15.7-70.3$ & \\
\hline \multicolumn{4}{|c|}{ Neoadjuvant chemotherapy } \\
\hline Yes & 17 & $9.2-24.8$ & \multirow[t]{2}{*}{0.57} \\
\hline None & 23 & $16.1-29.9$ & \\
\hline \multicolumn{4}{|c|}{ Taxanes (neoadjuvant/adjuvant setting) } \\
\hline Yes & 23 & $16.5-29.5$ & \multirow[t]{2}{*}{0.81} \\
\hline No & 18 & $9.2-26.8$ & \\
\hline
\end{tabular}

MOS = Median overall survival; $\mathrm{CI}=$ confidence interval

tients with $\mathrm{p} 53$-positive disease was only 17 months ( $\mathrm{p}=$ 0.01 ; fig. 2). The median OS for patients with visceral disease was 17 months versus 43 months for those without visceral organ involvement ( $\mathrm{p}=0.003$; fig. 3$)$. $\mathrm{p} 53$ positivity was similar in patients with visceral and nonvisceral metastasis (53 and 47\%, respectively, $\mathrm{p}=0.75$, using Fisher exact test). In patients with visceral disease, the median OS was 15 months for patients with p53-positive tumors and 20 months for patients with $\mathrm{p} 53$-negative tumors $(\mathrm{p}=0.11)$. The median OS for patients with $\mathrm{p} 53$ positive and p53-negative tumors was 27 months and 43 months, respectively $(\mathrm{p}=0.12)$, in the group with nonvisceral disease. 


\section{Discussion}

In this study, it has been shown that $\mathrm{p} 53$ protein accumulation and presence of visceral organ involvement are predictors of poor survival in metastatic IBC.

The prevalence of p53 mutations appeared higher in IBC than in nonIBC. In previous studies, p53 mutations had been shown in $30-69 \%$ of IBC $[6-9,11]$. In our study, p53 accumulation was seen in $51 \%$ of the patients, thereby confirming the prognostic significance of p53 mutations in IBC. As pointed out by Riou et al. [6], IBC patients with a mutant $\mathrm{p} 53$ gene and $\mathrm{p} 53$ protein overexpression had an 8.6-fold increased risk of death when compared to the patients with neither gene mutations nor protein overexpression [6]. In this study, the risk of death was found to be even higher when ER was negative in addition to the p53 abnormality.

In this study, p53 protein accumulation was assessed by IHC. This method relies on the detection of the protein encoded by a mutated p53 gene which is not degraded as quickly as the wild-type protein. p53 mutations which generate truncated proteins, like nonsense and splicing mutations, do not correlate well with p53 overexpression by IHC [12]. However, these mutations are rarely observed [13]. Currently, IHC is the most commonly used modality for the evaluation of p53 mutations because sequencing of the p53 gene in all breast cancers would be expensive and time consuming in daily practice. Therefore, p53 determination by IHC as used in this study provides a practical tool to assess prognosis in metastatic IBC.

In studies of metastatic breast cancer, it has been shown that hormone receptor status, performance status, patient age, tumor grade, c-erbB-2 overexpression, num- ber of metastatic sites, visceral metastasis and diseasefree survival are predictors of survival [14-17]. In our study, presence of visceral metastasis was the only other significant predictor of poor survival. Because of the rarity of the disease, published studies of IBC [5-9] have been retrospective in nature and have typically involved $<100$ patients. Larger multiinstitutional prospective studies are needed to confirm our observations and determine whether other prognostic markers exist that may have been missed in smaller studies.

One reason for the poor prognosis of p53 mutated IBC may be the relative resistance of $\mathrm{p} 53$-positive tumors to chemotherapy, although this issue is a matter of ongoing debate. Studies on 553 mutations and chemosensitivity in breast cancer have produced inconsistent results $[18,19]$. Most trials have shown that $\mathrm{p} 53$ is a negative predictor of response to anthracyclines [19-23]. Fewer studies have focused on the predictive value of $\mathrm{p} 53$ for response to taxanes. The results of these studies have been inconclusive [24-28].

\section{Conclusion}

These results indicate that as in noninflammatory metastatic breast cancer, IBC is a heterogeneous disease with regard to prognosis. Patients with p53 protein accumulation and visceral organ involvement appear to have a life expectancy significantly shorter than those without these poor prognostic features. p53 status and presence or absence of visceral metastasis constitute a clinically useful tool to estimate prognosis and for risk stratification in metastatic IBC. However, larger prospective studies will be needed to confirm these findings.

\section{References}

1 Chang S, Parker SL, Pham T, Buzdar AU, Hursting SD: Inflammatory breast carcinoma incidence and survival: the surveillance, epidemiology, and end results program of the National Cancer Institue, 1975-1992. Cancer 1998;82:2366-2372.

2 Haagenson CD: Diseases of the Breast, ed 2. Philadelphia, Saunders, 1971, pp 576584.

3 Taylor G, Meltzer A: Inflammatory carcinoma of the breast. Am J Cancer 1938;33:3349.

4 Cristofanilli M, Buzdar AU, Hortobagyi GN: Update on the management of inflammatory breast cancer. Oncologist 2003;8:141-148. $\checkmark 5$ Buzdar AU, Singletary SE, Booser DJ, Frye DK, Wasaff B, Hortobagyi GN: Combined modality treatment of stage III and inflammatory breast cancer: M D Anderson Cancer Center experience. Surg Oncol Clin N Am 1995;4:715-734

-6 Riou G, Le MG, Travagli JP, Levine AJ, Moll UM: Poor prognosis of p53 gene mutation and nuclear overexpression of p53 protein in inflammatory breast carcinoma. J Natl Cancer Inst 1993;85:1765-1767.
7 Bonnefoi H, Diebold-Berger S, Therasse P, Hamilton A, van de Vijver M, MacGrogan G, Shepherd L, Amaral N, Duval C, Drijkoningen R, Larsimont D, Piccart M: Locally advanced/inflammatory breast cancers treated with intensive epirubicin-based neoadjuvant chemotherapy: are there molecular markers in the primary tumour that predict for 5-year clinical outcome? Ann Oncol 2003;14:406413.

8 Gonzalez-Angulo AM, Sneige N, Buzdar AU, Valero V, Kau SW, Broglio K, Yamamura Y, Hortobagyi GN, Cristofanilli M: p53 expression as a prognostic marker in inflammatory breast cancer. Clin Cancer Res 2004; 10:6215-6221. 
>9 Sawaki M, Ito Y, Akiyama F, Tokudome N, Horii R, Mizunuma N, Takahashi S, Horikoshi N, Imai T, Nakao A, Kasumi F, Sakamoto G, Hatake K: High prevalence of HER-2/neu and p53 overexpression in inflammatory breast cancer. Breast Cancer 2006;13:172178.

10 World Health Organization: WHO Handbook for Reporting Results of Cancer Treatment. Geneva, World Health Organization, 1979.

-11 Faille A, De Cremoux P, Extra JM, Linares G, Espie M, Bourstyn E, De Rocquancourt A, Giacchetti S, Marty M, Calvo F: p53 mutations and overexpression in locally advanced breast cancers. Br J Cancer 1994;69:11451150 .

-12 Eicheler W, Zips D, Dorfler A, Grénman R, Baumann M: Splicing mutations in TP53 in human squamous cell lines influence immunohistochemical detection. J Histochem Cytochem 2002;50:197-203.

-13 Logullo AF, de Moura RP, Nonogaki S, Kowalski LP, Nagai MA, Simpson AJ: A proposal for the integration of immunohistochemical staining and DNA-based techniques for the determination of TP53 mutations in human carcinomas. Diagn Mol Pathol 2000;9: 35-40.

-14 Clark G, Sledge GWJ, Osborne CK, McGuire WL: Survival from first recurrence: relative importance of prognostic factors in 1015 breast cancer patients. J Clin Oncol 1987;5: 55-61.

15 Insa A, Lluch A, Prosper F, Marugan I, Martinez-Agullo A, Garcia-Conde J: Prognostic factors predicting survival from first recurrence in patients with metastatic breast cancer: analysis of 439 patients. Breast Cancer Res Treat 1999;56:67-78.
6 Chang J, Clark GM, Allred DC, Mohsin S, Chamness G, Elledge RM: Survival of patients with metastatic breast carcinoma: importance of prognostic markers of the primary tumor. Cancer 2003;97:545-553.

17 Efficace F, Biganzoli L, Piccart M, Coens C, Van Steen K, Cufer T, Coleman RE, Calvert HA, Gamucci T, Twelves C, Fargeot P, Bottomley A; EORTC-BCG-IDBBC-NDDG; EORTC-BCG-IDBBC-NDDG: Baseline health-related quality-of-life data as prognostic factors in a phase III multicentre study of women with metastatic breast cancer. Eur J Cancer 2004;40:1021-1030.

18 Elledge RM, Allred DC: Prognostic and predictive value of $\mathrm{p} 53$ and $\mathrm{p} 21$ in breast cancer. Breast Cancer Res Treat 1998;52:79-98.

19 Lacroix M, Toillon RA, Leclercq G: p53 and breast cancer, an update. Endocr Relat Cancer 2006;13:293-325.

20 Bottini A, Berruti A, Bersiga A, Brizzi MP, Brunelli A, Gorzegno G, DiMarco B, Aguggini S, Bolsi G, Cirillo F, Filippini L, Betri E, Bertoli G, Alquati P, Dogliotti L: p53 but not bcl-2 immunostaining is predictive of poor clinical complete response to primary chemotherapy in breast cancer patients. Clin Cancer Res 2000;6:2751-2758.

-21 Clahsen PC, van de Velde CJ, Duval C, Pallud C, Mandard AM, Delobelle-Deroide A, van den Broek L, Sahmoud TM, van de Vijver MJ: p53 protein accumulation and response to adjuvant chemotherapy in premenopausal women with node-negative early breast cancer. J Clin Oncol 1998;16: 470-479.
22 Mottolese M, Benevolo M, Del Monte G, Buglioni S, Papaldo P, Nisticò C, Di Filippo F, Vasselli S, Vici P, Botti C: Role of P53 and BCL-2 in high-risk breast cancer patients treated with adjuvant anthracycline-based chemotherapy. J Cancer Res Clin Oncol 2000;126:722-729.

-23 Rahko E, Blanco G, Soini Y, Bloigu R, Jukkola A: A mutant TP53 gene status is associated with a poor prognosis and anthracycline resistance in breast cancer patients. Eur J Cancer 2003;39:447-453.

$>24$ Wahl AF, Donaldson KL, Fairchild C, Lee FY, Foster SA, Demers GW, Galloway DA: Loss of normal p53 function confers sensitization to Taxol by increasing G2/M arrest and apoptosis. Nat Med 1996;2:72-79.

25 Sjostrom J, Blomqvist C, Heikkila P, Boguslawski KV, Räisänen-Sokolowski A, Bengtsson NO, Mjaaland I, Malmström P, Ostenstadt B, Bergh J, Wist E, Valvere V, Saksela E: Predictive value of $\mathrm{p} 53, \mathrm{mdm}-2, \mathrm{p} 21$, and mib-1 for chemotherapy response in advanced breast cancer. Clin Cancer Res 2000; 6:3103-3110.

26 Schmidt M, Bachhuber A, Victor A, Steiner E, Mahlke M, Lehr HA, Pilch H, Weikel W, Knapstein PG: p53 expression and resistance against paclitaxel in patients with metastatic breast cancer. J Cancer Res Clin Oncol 2003; 129:295-302.

27 Anelli A, Brentani RR, Gadelha AP, Amorim De Albuquerque A, Soares F: Correlation of p53 status with outcome of neoadjuvant chemotherapy using paclitaxel and doxorubicin in stage IIIB breast cancer. Ann Oncol 2003; 14:428-432.

-28 Sezgin C, Karabulut B, Uslu R, Sanli UA, Goksel G, Zekioglu O, Ozdemir N, Goker E: Potential predictive factors for response to weekly paclitaxel treatment in patients with metastatic breast cancer. J Chemother 2005; 17:96-103. 